\title{
Level of Awareness of Cervical and Breast Cancer Risk Factors and Safe Practices among College Teachers of Different States in India: Do Awareness Programmes Have an Impact on Adoption of Safe Practices?
}

\author{
Abhishek Shankar ${ }^{1 *}$, GK Rath ${ }^{1}$, Shubham Roy ${ }^{2}$, Abhidha Malik ${ }^{1}$, Ruchir \\ Bhandari $^{1}$, Kunal Kishor ${ }^{1}$, Keshav Barnwal ${ }^{3}$, Sneha Upadyaya ${ }^{3}$, Vivek \\ Srivastava ${ }^{3}$, Rajan Singh $^{3}$
}

\begin{abstract}
Background: Breast and cervical cancers are the most common causes of cancer mortality among women in India, but actually they are largely preventable diseases. Although early detection is the only way to reduce morbidity and mortality, there are limited data on breast and cervical cancer knowledge, safe practices and attitudes of teachers in India. The purpose of this study is to assess the level of awareness and impact of awareness programs in adoption of safe practices in prevention and early detection. Materials and Methods: This assessment was part of a pink chain campaign on cancer awareness. During cancer awareness events in 2011 at various women colleges in different parts in India, a pre-test related to cervical cancer and breast cancer was followed by an awareness program. Post-tests using the same questionnaire were conducted at the end of the interactive session, at 6 months and 1 year. Results: A total of 156 out of 182 teachers participated in the study (overall response rate was $85.7 \%$ ). Mean age of the study population was 42.4 years (range- 28-59 yrs). There was a significant increase in level of knowledge regarding cervical and breast cancer at 6 months and this was sustained at 1 year. Adoption of breast self examination (BSE) was significantly more frequent in comparison to CBE, mammography and the Pap test. Magazines and newspapers were sources for knowledge regarding screening tests for breast cancer in more than $60 \%$ of teachers where as more than $75 \%$ were educated by doctors regarding the Pap test. Post awareness at 6 months and 1 year, there was a significant change in alcohol and smoking habits. Major reasons for not doing screening test were found to be ignorance $(50 \%)$, lethargic attitude $\mathbf{( 4 4 . 8 \% )}$ ) and lack of time (34.6\%). Conclusions: Level of knowledge of breast cancer risk factors, symptoms and screening methods was high as compared to cervical cancer. There was a significant increase in level of knowledge regarding cervical and breast cancer at 6 months and this was sustained at 1 year. Adoption of BSE was significantly greater in comparison to $\mathrm{CBE}$, mammography and the Pap test. To inculcate safe practices in lifestyle of people, awareness programmes such as pink chain campaign should be conducted more widely and frequently.
\end{abstract}

Keywords: Breast and cervical cancer - awareness campaign - college teachers - safe practices

Asian Pac J Cancer Prev, 16 (3), 927-932

\section{Introduction}

Cancer is a major public health problem both in our country and worldwide due to its disease burden, fatality and tendency for increased incidence (Akgun Sahin et al., 2013). Globally, cervical cancer is the second most prevalent cancer and third most common type of cancer after breast and lung cancers among women (Sogukpinar et al., 2013). The global burden of cervical cancer is disproportionately high among the developing countries where $85 \%$ of the estimated 493,000 new cases and 273, 000 deaths occur world-wide. (Ali et al., 2012). India, which accounts for one sixth of the world's population, also bears one fifth of World's burden of cervical cancer (Barillot et al., 2000). Over the past 40 years mortality from carcinoma of the cervix has fallen due to improved treatment and the introduction of national screening programs (Davidson et al., 2002). Pap smear test is the main screening method used for the secondary prevention of cervical cancer. It can detect precancerous cells easily

${ }^{1}$ Department of Radiation Oncology, Dr. B.R. Ambedkar Institute Rotary Cancer Hospital, All India Institute of Medical Sciences, Delhi, ${ }^{2}$ Department of Pediatrics, VMMC \& Safdarjung Hospital, New Delhi, ${ }^{3}$ Pink Chain Campaign, Punarjeevan, Bihar, India *For correspondence:doc.abhishankar@gmail.com 
(Kotaniemi-Talonen et al., 2008). The Pap smear testing is an effective method of detecting, preventing and delaying the progress of cervical cancer (Bebis et al., 2012; Sogukpinar et al., 2013).

Breast cancer is recognized as the commonest cancer in females, and the second commonest malignant tumor, after lung cancer, in overall figures worldwide (Jemal et al., 2011). Breast cancer is the most common type of cancer among women with the highest fatality rates (Koca et al., 2013; Kratzke et al., 2013; Oztunc et al., 2013). Considering that breast cancer is the most common type of cancer among women with an increasing incidence, there is a need to develop community-based, wellorganized screening programs for breast cancer instead of coincidental screening of women (Acikgoz et al., 2011) because early diagnosis is the most effective way to reduce morbidity and mortality of breast cancer (Kanaga et al., 2011). Breast self-examination (BSE), clinical breast examination and mammography are recommended for detecting breast cancer at an early stage (Yilmaz et al., 2013). The practice of BSE every month has been reported to be considerably important for early detection of breast cancer particularly among women over 20 years of age (Koc and Saglam, 2009).

Breast and cervical cancers are the most common causes of cancer mortality among women in India, but actually they are largely preventable diseases (Tripathi et al., 2014). With rapid industrialization and effective control of communicable diseases, better diagnostic and treatment facilities, cancer is emerging as a major health problem and most of the cases are presenting very late to the hospital (Rebentisch et al., 1995).

Awareness and health seeking practices have been shown to be poor in many developing countries, necessitating the need for proper awareness programs (Montezari et al., 2008; Khokhar, 2009). With improvement in cancer technology, we have been able to manage to improve quality of life but improvement in survival is still questionable. In India, late presentation is attributed to many factors and important being the lack of knowledge and awareness, lethargic attitude towards safe practices.

However, several studies have shown that the knowledge of breast and cervical cancers and practices regarding for early detection are at a low level among women. Since early detection is the only way to reduce morbidity and mortality from breast cancer and cervical cancer, there is limited data on breast and cervical cancer knowledge, safe practices and attitudes of teachers in India. The purpose of this study is to know the level of awareness of cervical and breast cancer risk factors and safe practices among college teachers of different states of India and impact on awareness program on changing in adoption of safe practices in prevention and early detection.

\section{Materials and Methods}

This assessment was part of pink chain campaignA campaign on cancer awareness. During the cancer awareness events in 2011 at various women colleges in Jaipur and Mumbai in India, Pre test related to knowledge, attitude and practice related to cervical cancer and breast cancer was conducted before the start of the event through questionnaire.

Pre test was followed by awareness program consisting of lectures on preventive aspects of breast and cervical cancer, Pink Chain-a docu-drama on breast cancer and an interactive session. Post test using the same questionnaire was conducted at the end of interactive session. For all the teachers who participated in the awareness program, personal details were collected. At the end, screening program was organized to do clinical breast examination, pelvic examination with consent and to teach how to do breast self examination.

After completion of 6 months and 1 year, same questionnaires were mailed to the participants on their

Table 1. Knowledge Regarding Various Aspects of Carcinoma Cervix

\begin{tabular}{|c|c|c|c|c|c|}
\hline Knowledge about carcinoma cervix & $\begin{array}{l}\text { Frequency }(\%) \\
\text { Pre test }(n=156)\end{array}$ & $\begin{array}{c}\text { Frequency }(\%) \\
\text { Post test }(\mathrm{n}=156)\end{array}$ & $\begin{array}{c}\text { Frequency }(\%) \\
\text { At } 6 \text { months }(\mathrm{n}=109)\end{array}$ & $\begin{array}{c}\text { Frequency }(\%) \\
\text { At } 1 \text { year }(\mathrm{n}=95)\end{array}$ & $\mathrm{p}$ value \\
\hline Symptoms & & & & & $<0.05$ \\
\hline Menstrual abnormality & $50(32)$ & $150(96.1)$ & $102(93.5)$ & $94(98.9)$ & \\
\hline Vaginal discharge & $42(26.9)$ & $140(89.7)$ & $104(95.4)$ & $93(97.8)$ & \\
\hline Pain(pelvic,back,leg) & $26(16.6)$ & $138(88.4)$ & $102(93.5)$ & $93(97.8)$ & \\
\hline Bleeding from rectum or bladder & $12(7.69)$ & $128(82)$ & $100(91.7)$ & $90(94.7)$ & \\
\hline Risk Factors & & & & & $<0.05$ \\
\hline Human papilloma virus infection & $48(30.7)$ & $152(97.4)$ & $108(99)$ & $95(100)$ & \\
\hline Multiple sexual partners & $42(26.9)$ & $150(96.1)$ & $107(98.1)$ & $95(100)$ & \\
\hline Smoking & $80(51.2)$ & $150(96.1)$ & $108(99)$ & $94(98.9)$ & \\
\hline Decrease Immunity & $12(7.69)$ & $140(89.7)$ & $104(95.4)$ & $92(96.8)$ & \\
\hline Oral contraceptives & $10(6.41)$ & $146(93.5)$ & $105(96.3)$ & $93(97.8)$ & \\
\hline Early marriage & $22(14.1)$ & $152(97.4)$ & $109(100)$ & $95(100)$ & \\
\hline Early pregnancy & $20(12.8)$ & $154(98.7)$ & $109(100)$ & $95(100)$ & \\
\hline Multiple pregnancies & $21(13.4)$ & $152(97.4)$ & $109(100)$ & $95(100)$ & \\
\hline Genital hygiene & $56(35.8)$ & $156(100)$ & $109(100)$ & $95(100)$ & \\
\hline Family H/O cervical cancer & $70(44.8)$ & $150(96.1)$ & $108(99)$ & $94(98.9)$ & \\
\hline Preventive Measures & & & & & $<0.05$ \\
\hline Good genital hygiene & $62(39.7)$ & $156(100)$ & $109(100)$ & $95(100)$ & \\
\hline Use of condom & $90(57.6)$ & $154(98.7)$ & $109(100)$ & $95(100)$ & \\
\hline PAP test & $54(34.6)$ & $156(100)$ & $109(100)$ & $95(100)$ & \\
\hline
\end{tabular}


Level of Awareness of Cervical and Breast Cancer Risk Factors and Safe Practices among College Teachers in India

email ids provided at the time of program to see the change in practice.

\section{Results}

A total of 156 out of 182 teachers participated in the study (overall response rate was $85.7 \%$ ). 26 teachers assessment form were either not filled or incomplete. In the information provided, Email ids were available of 132 teachers. Same questionnaire were responded by 109 and 95 teachers at the end of 6 months and 1 year respectively. Mean age of the study population was 42.4 years (range-28-59 yrs). $86 \%$ teachers were in age group 31-50 years. Most of the teachers (88.4\%) were from urban background. Among teachers who were assessed, 17 teachers $(10.8 \%)$ were smokers and 41 teachers $(26.2 \%)$ were alcoholics.

No shift from non-addiction group to addiction group was noted at 6 months and 1 year. In people who were smoking $(11 \%)$ and taking alcohol $(26 \%)$ before this campaign, change in addiction habit was noted at 6 months and 1 year. Decrease in frequency was seen in $11.7 \%$ for smoking and $17 \%$ for alcohol at 1 year. Approximately 18 $\%$ and $30 \%$ teachers quit smoking and alcohol respectively at the end of 1 year.

For cervical cancer, the correct risk factors mostly indicated by teachers were smoking (53\%), family $\mathrm{H} / \mathrm{O}$ cervical cancer (45\%) and genital hygiene (36\%). Symptoms of cervical cancer were very less known to teachers (7.69\%-32\%). Risk factors and symptoms of breast cancer were well known in more than $50 \%$ of teachers, except for early menarche $(16.66 \%)$, late menopause (17.9\%) and radiation treatment $(14.1 \%)$.

As for screening methods, BSE, CBE, and Mammography were known modalities for breast cancer in $70 \%, 45 \%$ and $54 \%$ of teachers respectively but pap's test was known to only $35 \%$.

Knowledge about breast self examination (BSE) was significantly increased at 6 months and sustained at 1 year. Among teachers with knowledge, practice of BSE was increased from $11 \%$ to $52 \%$ at 6 months and $59 \%$ at 1 year.

Knowledge of clinical breast examination (CBE) was gradually increased from $20 \%$ to $23 \%$ at 6 months and to $26 \%$ at 1 year. Practices were not changed among teachers with knowledge of CBE. Practice of mammography increased from $14 \%$ to $22 \%$ in teachers with knowledge of mammography at 6 months but no change in practice at 1 year.

For cervical cancer screening, knowledge and practice of Pap test as screening test for cervical cancer among teachers were changed significantly at 6 months and 1 year.

Magazines and newspapers were source for knowledge regarding screening test for breast cancer in more than $60 \%$ of teachers where as more than $75 \%$ teachers were educated by doctors regarding pap's test. Post awareness

Table 3. Source of Knowledge Regarding Screening Tests in Breast and Cervical Cancer

\begin{tabular}{lcclr}
\hline & BSE & CBE & $\begin{array}{c}\text { Mammo- } \\
\text { graphy } \\
(\mathrm{n}=84)\end{array}$ & $\begin{array}{c}\text { Pap's } \\
\text { smear } \\
(\mathrm{n}=54)\end{array}$ \\
\hline Family & $10(9.17)$ & $2(2.85)$ & $6(7.14)$ & $9(16.6)$ \\
Friends & $23(21.1)$ & $4(5.71)$ & $18(21.4)$ & $17(31.4)$ \\
Doctors & $24(22)$ & $21(30)$ & $42(50)$ & $41(75.9)$ \\
TV & $12(11)$ & $2(2.85)$ & $17(20.2)$ & $10(18.5)$ \\
News papers & $56(51.3)$ & $35(50)$ & $53(63)$ & $22(40.7)$ \\
Magazine & $63(57.7)$ & $43(61.4)$ & $49(58.3)$ & $38(70.3)$ \\
Internet & $34(31.1)$ & $22(31.4)$ & $38(45.2)$ & $19(35.1)$ \\
Awareness events & $14(12.8)$ & $4(5.71)$ & $11(13)$ & $8(14.8)$ \\
Any other & $05(4.58)$ & $2(2.85)$ & $3(3.57)$ & $1(1.85)$ \\
\hline
\end{tabular}

Table 2. Knowledge Regarding Various Aspects of Carcinoma Breast

\begin{tabular}{|c|c|c|c|c|c|}
\hline Knowledge about carcinoma cervix & $\begin{array}{l}\text { Frequency }(\%) \\
\text { Pre test } \\
(n=156)\end{array}$ & $\begin{array}{c}\text { Frequency }(\%) \\
\text { Post test } \\
(\mathrm{n}=156)\end{array}$ & $\begin{array}{l}\text { Frequency }(\%) \\
\text { At } 6 \text { months } \\
\quad(n=109)\end{array}$ & $\begin{array}{c}\text { Frequency }(\%) \\
\text { At } 1 \text { year } \\
(n=95)\end{array}$ & $\mathrm{p}$ value \\
\hline Symptoms & & & & & $<0.05$ \\
\hline Lump, hard knot or thickening & $130(83.3)$ & $156(100)$ & $109(100)$ & $95(100)$ & \\
\hline Redness, warmth or darkening & $95(60.8)$ & $152(97.4)$ & $108(99)$ & $93(97.8)$ & \\
\hline Change in the size or shape of nipple or breast & $\mathrm{t} \quad 102(65.3)$ & $154(98.7)$ & $107(98.1)$ & $94(98.9)$ & \\
\hline Dimpling or puckering of the skin or nipple & $80(51.2)$ & $150(96.1)$ & $106(97.2)$ & $94(98.9)$ & \\
\hline Nipple discharge that starts suddenly & $76(48.7)$ & $151(96.7)$ & $108(99)$ & $95(100)$ & \\
\hline Risk factors & & & & & $<0.05$ \\
\hline Advancing age & $70(44.8)$ & $150(96.1)$ & $108(99)$ & $94(98.9)$ & \\
\hline Genetic factors & $58(37.1)$ & $156(100)$ & $104(95.4)$ & $90(94.7)$ & \\
\hline Family history of breast cancer & $102(65.3)$ & $156(100)$ & $109(100)$ & $95(100)$ & \\
\hline Radiation treatment & $22(14.1)$ & $152(97.4)$ & $107(98.1)$ & $93(97.8)$ & \\
\hline Early menarche $(<12$ yr $)$ & $26(16.6)$ & $150(96.1)$ & $105(96.3)$ & $94(98.9)$ & \\
\hline Late menopause (>50yr) & $28(17.9)$ & $152(97.4)$ & $105(96.3)$ & $93(97.8)$ & \\
\hline Nulliparous(No child) & $36(23)$ & $150(96.1)$ & $105(96.3)$ & $94(98.9)$ & \\
\hline First childbirth at $>30$ yrs. & $34(21.7)$ & $150(96.1)$ & 105 (96.3) & $94(98.9)$ & \\
\hline Oral contraceptives & $27(17.3)$ & $150(96.1)$ & $107(98.1)$ & $93(97.8)$ & \\
\hline No breast feeding & $12(7.69)$ & $150(96.1)$ & $107(98.1)$ & $94(98.9)$ & \\
\hline Obesity & $82(52.5)$ & $156(100)$ & $109(100)$ & $95(100)$ & \\
\hline Smoking & $102(65.3)$ & $156(100)$ & $109(100)$ & $95(100)$ & \\
\hline Preventive measures & & & & & $<0.05$ \\
\hline BSE & $109(69.8)$ & $156(100)$ & $109(100)$ & $95(100)$ & \\
\hline CBE & $70(44.8)$ & $156(100)$ & $109(100)$ & $95(100)$ & \\
\hline Mammography & $84(53.8)$ & $156(100)$ & $109(100)$ & $95(100)$ & \\
\hline
\end{tabular}


at 6 months and 1 year, there was a significant change in alcohol and smoking habits. For not doing screening test, major reasons came out to be ignorance $(50 \%)$, lethargic attitude (44.8\%) and lack of time (34.6\%).

\section{Discussion}

The total annual reported number of cases diagnosed with breast cancer globally exceeds 1 million and this number is expected to increase to 1.5 million by the end of decade (Love et al., 2004). Total 156 out of 182 women between 28-59 years of were included in the study. 26 teachers assessment form was not suitable for analysis. At the end of 6 months and one year, 109 and 95 teachers participated in study. The risk factors and symptoms of breast cancer and cervical cancer were generally not well known in beginning. There was gradual increase in knowledge and practice of breast cancer and cervical cancer at 6 months and was sustained at one year. Even though cancer cervix is the most common cancer affecting rural Indian women, awareness about symptoms, early diagnosis, and screening test was very poor.

The prerequisite for early diagnosis is to have knowledge about the symptoms of cancer so as to consult doctor at the earliest (Fang et al., 2011). Nearly two-third of the women was unaware of the risk factors for cancer cervix in our study. Similar findings were noted by other study (Saha et al., 2010). Another study by Basu et al in 2014 in which cervical cancer was known to only $38 \%$ (Basu et al., 2014).

A study from North Bengal, India by Raychoudhuri and Mandal showed that $87 \%$ women were aware of the term cancer, and few about cervical cancer. It was observed that $96.4 \%$ of the population were unaware of the causes of the disease, $93.7 \%$ were not aware of the signs and symptoms and $96.4 \%$ of the prevention of cervical cancer (Raychoudhuri and Mandal, 2012).

In a study by Siddharthar et al. showed that less than half of the study population was aware of cervical cancer and only one-third of the women had knowledge about its risk factors and symptoms. Smoking cigarettes (10.3\%), long term use of oral contraceptive pill $(16.3 \%)$, poor genital hygiene $(7.5 \%)$, having a sexual partner with multiple partners $(15 \%)$ were considered the major risk factors for cervical cancer. Of the symptoms of cervical cancer, bleeding during or after sex $(15.3 \%)$, vaginal bleeding after menopause $(10.3 \%)$, pain during sex $(10 \%)$ and persistent low back pain $(9.8 \%)$ were considered more frequently by the women. Only $7.3 \%$ of the women considered themselves at risk of cervical cancer.

Amomg the preventive measures, Paps test was known to only $35 \%$ of teachers in this study. In a study by Raychoudhuri and Mandal, $90.5 \%$ were unaware of the Pap test as a screening procedure although $84.6 \%$ were willing to undergo the test as they felt it would benefit them in the long run. This is in agreement with a study conducted in Kolkata (Roy and Tang, 2008).

Important risk factors for breast cancer include gender, age, family and genetic factors, a history of breast cancer, race, exposure to radiation, younger age at menarche (12 years of age) and age at menopause (Older than 55 years of age). Additional risk factors related to development of breast cancer include nulliparity or pregnancy after the age of 30, ovarian activity, use of oral contraceptives, receiving hormone replacement therapy after menopause, lactation, alcohol consumption, obesity and high-fat diets and physical activity (Amusu et al., 2011; Kanbur and Capik, 2011; Koca et al., 2013).

Awareness was low about symptoms (50\%), but was better than cancer cervix (35\%). Another study by Naim Nur showed similar kind of finding about knowledge of breast cancer where he found that up to one-half (52.4\%) of the teachers thought that they had enough knowledge about breast cancer (Naim Nur, 2010). In a study by Shrestha K showed that only $30 \%$ people in the study heard about breast cancer and $70 \%$ were having no idea about it (Shrestha, 2012).

Most known symptom was lump in breast. BSE awareness was very good $(70 \%)$ however teachers were not well aware about CBE (45\%) and mammography $(54 \%)$. Nearly half of women failed to opine for availing the early diagnostic services may be because of lack of awareness. Awareness about risk factors for cancer breast was very low (30\%), which may be hurdle for prevention. Similar findings were noted by other studies (Akhigbe and Omuemu, 2009).

Among the screening modalities for breast cancer, BSE was practiced by only $11 \%$ of teachers. Similar finding was shown in a study by Parsa et al in 2011 where Only $19 \%$ of the women performed BSE on a regular basis (Parsa and Parsa, 2011). In a study by Dandash and Al-Mohaimeed (2007) $43.4 \%$ of the female teachers were found to have never performed BSE and Montazeri et al.'s study (2008) found that $63.0 \%$ of the women never performed a BSE in their lifetime.

Mammography and paps smear were exercised by $14 \%$ and $17 \%$ of teachers respectively. In a study by AbdelHadi on school teachers in Saudi Arabia in 2006 in which only 14\% were practicing mammography (AbdelHadi, 2006).

It is important to improve awareness about breast cancer and screening methods for promoting early screening. Policymakers need to make key decisions which among three methods (breast self examination (BSE), clinical breast examination and mammography) can best be used as a screening tool and how to successfully implement population wide screening program to prevent mortality and morbidity from breast cancer in India (Bodapati and Babu, 2013)

Source of knowledge of screening modalities for breast and cervical cancer were magazines, newspapers, internet in majority of cases but doctors were important source for mammography and paps smear. In a Jordanian study, out of the 435 respondents who were aware of breast cancer, $51.8 \%$ obtained their information on breast cancer from friends and health workers. (Suleiman, 2014)

According to women, main barrier for using early diagnostic services for breast and cervical cancer was lack of awareness about symptoms and availability of tests, and therefore, the possibility of early diagnosis. Similar findings were mentioned by other studies (Saha et 
al., 2010). Poor awareness lowers the possibility of early diagnosis in spite of availability of screening test. Nearly half of the women have shown attitude or willingness for using the early detection method if they are available. Hence, lack of awareness was the main hindrance for early detection.

In a study from Karachi, Pakistan regarding reasons for delay in breast cancer diagnosis, the most frequent reasons given by women for a delayed consultation were their perception regarding the symptoms to be harmless and temporary, adding, that at that time those did not appear to put any hindrance to their day to day activities, weren't apparently affecting their lives by causing pain or in any way and thought those would go away with time. This demonstrates poor knowledge of our females regarding importance of these warning signs and symptoms of breast cancer, that how much severity these symptoms can attain with the passage of time, being irreversible and even proving to be fatal in late stages (Memon et al., 2013).

It suggests that awareness through mass media may not be sufficient in changing attitude or practice. Other barriers were lethargic attitude (44.87\%), economic barrier (time and money), availability, fear and hesitation. Nessa et al showed that more emphasis must be given to use of print and audiovisual media in cervical and breast cancer prevention (Nessa et al., 2013). Tan et al. (2010) showed that mass media and education were the most common sources of information of cervical cancer. The section of population aware of cervical cancer came to know about this disease through friends or media like radio and television in a study in North Bengal, India (Raychoudhuri and Mandal, 2012).

Breast cancer and cervical cancer education continues to pose a challenge to the health care system in developing countries and countries with limited resources. Community-based cancer education requires intervention at many levels that address the fundamental causative contributing issues to the myriad of health disparities (Hurd et al., 2003).

In conclusion, the risk factors and symptoms of breast cancer and cervical cancer were generally not well known. Level of knowledge of breast cancer risk factors, symptoms and screening methods was high as compared to cervical cancer. There was a significant increase in level of knowledge regarding risk factors, symptoms and screening test for cervical and breast cancer at 6 months and this was sustained at 1 year. There was a significant increase in adoption of BSE where as practice of CBE, mammography and pap's test were increased significantly but less in comparison to BSE.

To inculcate safe practices in life style of people, awareness programmes such as pink chain campaign should be conducted more widely and frequently and knowledge attained through them should be reinforced by treating physicians who are at first point of contact with health system. So creating awareness among health care providers is another issue which has to be looked into.

It is important to create awareness among community through educational programs on cancer prevention, preventable cancer risk factors, benefits of early diagnosis, and availability of screening facilities.

\section{References}

AbdelHadi MS (2006). Breast cancer awareness campaign: Will it make a Difference? J Fam Community Med, 13, 115-8.

Acikgoz A, Cehreli R, Ellidokuz H (2011). Women's knowledge and attitude about cancerand the behaviour for early diagnosis procedures. DEU J Med Faculty, 25, 145-54.

Akgun Sahin Z, Tan M, Polat H (2013). Hopelessness, depression and social support with end of life Turkish cancer patients. Asian Pac J Cancer Prev, 14, 2823-8.

Akhigbe OA, Omuemu VO (2009). Knowledge, attitudes and practice of breast cancer screening among female health workers in a Nigerian urban city. BMC Cancer, 9, 203.

Akhtar SS, Lolita Malig Reyes (1997). Cancer in Al-Qassim, Saudi Arabia: A Retrospective Study (1987-1995). Ann Saudi Med, 17, 595-600.

Ali F, Kuelker R, Wassie B (2012). Understanding cervical cancer in the context of developing countries. Ann Trop Med Public Health, 5, 3-15.

Amosu AM, Degun AM, Thomas AM, Babalola AO (2011). Assessment of awareness, perception, specific knowledge, and screening behaviour regarding breast cancer among rural women in Ipokia Local Government Area, Ogun State, Nigeria. Arch Appl Sci Res, 3, 253-65.

Barillot I, Horiot JC, Maingon P, et al (2000). Impact on treatment outcome and late effects of customized treatment planning in cervix carcinomas: baseline results to compare new strategies. Int J Radiat Oncol Biol Phys, 48, 189-200.

Basu P ,Hassan S, Fileeshia F, et al (2014). Knowledge, attitude and practices of women in Maldives related to risk factors, prevention and Early detection of cervical cancer. Asian Pac J Cancer Prev, 15, 6691-5.

Bebis H, Reis N, Yavan T, Bayrak D, Unal A, Bodur S (2012). Effect of health education about cervical cancer and papanicolaou testing on the behavior, knowledge, and beliefs of Turkish women. Int J Gynecol Cancer, 22, 1407-12.

Bicen YH, Aksuyek H (2012). Fieldwork about importance of awareness in early diagnosis of breast cancer in Bursa. $J$ Breast Health, 8, 76-80.

Bodapati SL, Babu GR (2013). Oncologist perspectives on breast cancer screening in India - results from a qualitative study in Andhra Pradesh. Asian Pac J Cancer Prev, 14, 5817-23.

Coucke PA, Maingon P, Ciernik IF, Phuoc Do H( 2000). A survey on staging and treatment in uterine cervical carcinoma in the radiotherapy cooperative group of the European organization for research and treatment of cancer. Radiother Oncol, 54, 221-8.

Dandash KF, Al-Mohaimeed A (2007). Knowledge, attitudes, and practices surrounding breast cancer and screening in female teachers of Buraidah, Saudi Arabia. Int J Health Sci, 1, 61-71.

Davidson SE, Burns M, Routledge J, et al (2002). Short report: a morbidity scoring scheme for clinical oncology practice: questionnaire produced from the LENT SOMA scoring system. Clin Oncol, 14, 68-9.

Fang CY, Ma GX, Tan Y (2011). Overcoming barriers to cervical cancer screening among Asian American women. $N \mathrm{Am} J$ Med Sci, 4, 77-834.

Hurd T, Muti P, Erwin D, Womack (2003). An Evaluation of the integreation of non-traditional learning tools into a community based breast and cervical cancer education program: the witness project of Buffalo. BNC Cancer, 3,18 .

Jemal A, Bray F, Center MM, et al (2011). Global cancer statistics. CA Cancer J Clin, 61, 69-90.

Kanaga KC, Nithiya J, Shatirah MF (2011). Awareness of breast cancer and screening procedures among Malaysian women. Asian Pac J Cancer Prev, 12, 1965-7. 


\section{Abhishek Shankar et al}

Kanbur A, Capik C (2011). Cervical cancer prevention, early diagnosis-screening methods and midwives/nurses role. Hacettepe Univers Faculty Health Sci Nurs J, 18, 61-72.

Koc Z, Saglam Z (2009). Determination of the knowledge and the practice of female patients about breast cancer, preventive measures and breast self examination and effectiveness of education. J Breast Health, 5, 25-33.

Koca D, Ozdemir O, Akdeniz H, Unal OU, Yilmaz U (2013). Changes in the attitudes and behavior of relatives of breast cancer patients concerning cancer prevention and screening. Asian Pac J Cancer Prev, 14, 5693-7.

Khokhar A (2009). Level of awareness regarding breast cancer and its screening amongst Indian teachers. Asian Pac J Cancer Prev, 10, 247-50.

Kotaniemi-Talonen L, Anttila A, Malila N et al (2008). Screening with a primary human papillomavirus test does not increase detection of cervical cancer and intraepithelial neoplasia 3 . Eur J Cancer, 44, 565-71.

Kratzke C, Vilchis H,Amatya A (2013). Breast cancer prevention knowledge, attitudes, and behaviors among college women and mother-daughter communication. J Community Health, 38, 560-8.

Love R, Love S, Laudico A (2004). Breast cancer from a public health presepective. Breast J, 2, 136-40.

Memon ZA, Shaikh AN , Rizwan S, Sardar MB (2013). Reasons for patient's delay in diagnosis of breast carcinoma in Pakistan. Asian Pac J Cancer Prev, 14, 7409-14.

Montazeri A, Vahdaninia M, Harirchi I, et al (2008). Breast cancer in Iran: need for greater women awareness of warning signs and effective screening methods. Asia Pac Fam Med, 7, 6 .

Naim Nur (2010). Breast cancer knowledge and screening behaviors of the female teachers. Women Health, 150,37-52.

Nessa A, Hussain MA, Rashid MH, et al (2013). Role of print and audiovisual media in cervical cancer prevention in Bangladesh. Asian Pac J Cancer Prev, 14, 3131-7.

Oztunc G, Yesil P, Paydaş S, Erdogan S (2013). Social support and hopelessness in patients with breast cancer. Asian Pac J Cancer Prev, 14, 571-8.

Parkin DM, Bray F, Ferlay J, Pisani P (2005). Global cancer statistics, 2002. CA Cancer J Clin, 55, 74-108.

Parsa P, Kandiah M, Parsa N (2011). Factors associated with breast self-examination among Malaysian women teachers. East Mediterr Health J, 17, 509-16.

Raychaudhuri S, Mandal S (2012). Socio-demographic and behavioural risk factors for cervical cancer and knowledge, attitude and practice in rural and urban areas of North Bengal, India. Asian Pacific J Cancer Prev, 13, 1093-96.

Rebentisch DP, Rebentisch HD, Thomas K, Karat S, Jadhav AJ (1995). A proven and highly cost effective method of early detection of breast cancer for developing countries. Radiotherapy Oncol, 37, 246-8.

Reynolds T (1999). Declining breast cancer mortality: What behind it? J Natl Cancer Inst, 91, 750-3.

Roy B, Tang TS (2008). Cervical cancer screening in Kolkata, India: Beliefs and predictors of cervical cancer screening among women attending a women's health screening in Kolkata, India. J Cancer Edu, 23, 253-9

Saha A, Chaudhury AN, Bhowmik P, Chatterjee R (2010). Awareness of cervical cancer among female students of premier college in Kolkata, India. Asian Pac J Cancer Prev, 11, 1085-90.

Shrestha K (2012). Breast cancer knowledge and screening practice among women visited to KIST medical college. Nepal Med Coll J, 14, 308-11.

Siddharthar JR, Rajkumar B, Deivasigamani K (2014). Knowledge, awareness and prevention of cervical cancer among women attending a tertiary care hospital in puducherry, India. J Clin Diagnostic Res, 8, 1-3.

Sogukpinar N, Karaca Saydam B, Ozturk Can H, et al (2013). Assessment of cervical cancer risk in women between 15 and 49 years of age: Case of Izmir. Asian Pac J Cancer Prev, 14, 2119-25

Suleiman AK (2014). Awareness and attitudes regarding breast cancer and breast self examination among female Jordanian students. J Basic Clin Pharma, 5, 74-8.

Tabar L, Duffy SW, Vitak B, et al (1999). The natural history of breast carcinoma: What have we learned from screening? Cancer, 86, 449-62.

Tan YY Hesham R, Qodriyah HM (2010). Knowledge and attitude of university students in health sciences on the prevention of cervical cancer. Med J Malaysia, 65, 53-7.

Tripathi N, Kadam YR, Dhobale RV, Gore AD(2014). Barriers for detection of cancer amongst Indian rural women. South Asian J Cancer, 3, 122-7.

Yilmaz D, Bebis H, Ortabag T (2013). Determining the awareness of and compliance with breast cancer screening among Turkish residential women. Asian Pac J Cancer Prev, 14, 3281-8. 